\title{
CARACTERÍSTICAS CONSTITUYENTES DE LOS ACIERTOS Y DESACIERTOS FRENTE A LA CONFORMACIÓN DEL MOVIMIENTO ESTUDIANTIL \#YOSOY132
}

\section{Main Characteristics of Rights and Wrongs regarding the Student Movement \#YoSoy132}

Características constituintes dos acertos e desacertos perante à conformação do movimento estudantil \#YoSoy132

\section{RECIBIDO: 3 DE JULIO DE 2015}

José Javier Capera Figueroa (Colombia) Universidad del Tolima Politólogo

caperafigueroa@gmail.com

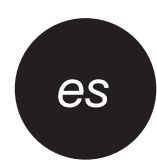

\section{RESUMEN}

El presente artículo analiza la categoría de movilización social a partir de los presupuestos teóricos y conceptuales de la literatura de los movimientos sociales para finales de siglo XIX e inicios del XX. En primer lugar, se propone realizar una reflexión sobre la noción conceptual de los nuevos movimientos sociales, en busca de una interrelación con las dinámicas del movimiento estudiantil \#YoSoy132 para 2012, pretendiendo así establecer una explicación teórica proveniente desde la ciencia política sobre los movimientos sociales, enfocándolo en el contexto latinoamericano de los movimientos estudiantiles. De esta manera, se recurre al análisis documental como criterio de abordaje del artículo, la revisión y reflexión teórica y sistemática de fuentes hemerográficas, asimismo este artículo deriva de una investigación concluida, realizada entre la Universidad del Tolima (Colombia) y la Universidad Autónoma del Estado de México (México). Finalmente, se plantearán algunas conclusiones que versarán sobre el movimiento estudiantil \#YoSoy132 y su correlación con la teoría de los movimientos sociales latinoamericanos..

PALABRAS CLAVE: movimientos sociales, movimiento estudiantil \#Yosoy132, nuevos movimientos sociales.

\section{EVALUADO:27 DE JULIO DE 2016}

Felipe Gabino Macedo (Colombia) Universidad Autónoma del Estado de México Estudiante de Maestría en Administración Pública y Gobierno

felipegabino24@hotmail.com

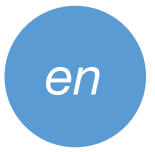

\section{ABSTRACT}

This article analyzes social mobilization from the theoretical and conceptual budgets of the literature that belongs to the social movements of the late XIX century and beginnings of the XX century. First of all, we reflect on the conceptual idea of new social movements, looking for an interrelation with the dynamics of the student movement \#YoSoy132 for 2012. This way, we aim to establish a theoretical explanation that comes from the political science of social movements, focusing it on the Latin American context of student movements. For this reason, we carry out a documental analysis, a revision, and a theoretical and systematic revision of articles in newspapers throughout the article. This article is also the result of an investigation carried out between Universidad del Tolima (Colombia) and Universidad Autónoma del Estado de México (Mexico). Finally, we formulate some conclusions regarding the student movement \#YoSoy132 and its relationship with the Latin American social movement theory.

KEYWORDS: Social movements, student movement \#Yosoy132, new social movements.

\section{ACEPTADO:29 DE JULIO DE 20166}

Sergio Alfonso Huertas Hernández (Colombia)

Universidad del Tolima Politólogo

sahuertas26@gmail.com

\section{por}

\section{RESUMO}

O presente artigo analisa a categoria de mobilização social a partir dos pressupostos teóricos e conceptuais da literatura dos movimentos sociais para finais do século XIX e inícios do XX. Em primeiro lugar, Propõe-se realizar uma reflexão sobre a noção conceptual dos novos movimentos sociais, em procura de uma inter-relação com as dinâmicas do movimento estudantil \#YoSoy132 para 2012, pretendendo assim estabelecer uma explicação teórica proveniente desde a ciência política sobre os movimentos sociais, focando-o no contexto latino-americano dos movimentos estudantis. Desta maneira, usa-se à análise documental como critério de abordagem do artigo, a revisão e reflexão teórica e sistemática de fontes hemerográficas, mesmo assim este artigo deriva de uma pesquisa concluída, realizada entre a Universidade do Tolima (Colômbia) e a Universidade Autónoma do Estado de México (México). Finalmente, se exporão algumas conclusões que versarão sobre o movimento estudantil \#YoSoy132 e a sua correlação com a teoria dos movimentos sociais latino-americanos.

PALAVRAS CHAVE: movimentos sociais, movimento estudantil \#Yosoy132, novos movimentos sociais 
Siendo así que la apuesta a re-pensar críticamente lo que es o no es un movimiento social implica disminuir la probabilidad de caer en reduccionismos o enunciaciones simples al categorizarlos per se, por lo que algunos teóricos los detallan desde su condición, las acciones dadas desde la histórica oral, la óptica periodística o en su defecto el giro conceptual de lo que constituyen los nuevos movimientos sociales o las dinámicas de la movilización de recursos en el escenario internacional.

En este caso, comprender críticamente los fenómenos de los movimientos sociales en América Latina, y específicamente de los movimientos estudiantiles, se convierte en una apuesta que los teóricos denominan "la base y organización de la estructura de un tipo de movimiento", en este caso una de las particularidades de los movimientos estudiantiles, resulta ser la característica proveniente de la crisis de los sistemas educativos, la falta de garantías por el ejercicio de las democracias y, sobre todo, la necesidad de construir una ciudadanía crítica, propositiva y reflexiva alrededor de las problemáticas estructurales de una nación (Marsiske, 1999, p. 12).

Los acontecimientos que presenció la ciudadanía mexicana en 2012 pusieron en tela de juicio el sistema político mexicano y gran parte de las estructuras de aquel entonces, razones que produjeron que un grupo de estudiantes en medio de la tensión (Javaloy, Carballeira y Espelt, 2001) contribuyera a la coyuntura político-electoral y, sobre todo, al ambiente en que se subsumía la ciudadanía mexicana, recurriendo a la organización social como estrategia de manifestación al demostrar su inconformidad, lo cual desató parte de la configuración del movimiento \#YoSoy132.

Este movimiento estudiantil se inició como resultado de las acciones de estudiantes inconformes frente a la campaña del candidato Enrique Peña Nieto, y así el 11 de mayo de 2012 fue un momento histórico vivido en la Universidad Iberoamericana, en el que coincidieron dos grupos de sectores sociales distintos en intereses y actitudes radicales. El primero identificado en los políticos del Partido Revolucionario Institucional (PRI) y el segundo en el grupo de estudiantes de la Universidad Iberoamericana que estuvieron en contra de la visita de Enrique Peña Nieto. Fue un hecho inédito no solo por haberse enfrentado estos dos grupos entre sí, sino por haber sido registrado y difundido masivamente en tiempo real por un sinfín de empresas periodísticas y aparatos electrónicos de los participantes (Sierra, 2014, p. 11).

Características constituyentes de los aciertos y desaciertos frente a la conformación del movimiento estudiantil \#YoSoy132

Una muestra de esto se identifica en la periodización que constituye la emergencia del movimiento en sus orígenes (Aranda, 2000), que muestra el siguiente panorama (tabla 1$)$ :

Tabla 1. Anexo de cronología sobre el movimiento \#YoSoy132 en México

\begin{tabular}{l|l}
\hline Difusión del evento en Facebook & 10 de mayo \\
\hline Protesta en la Universidad Iberoamericana & 11 de mayo \\
\hline $\begin{array}{l}\text { Edición de video donde alumnos de la } \\
\text { Universidad Iberoamericana se identifican }\end{array}$ & 12 y 13 mayo \\
\hline $\begin{array}{l}\text { Publicación del video “131 alumnos" de la } \\
\text { Universidad Iberoamericana responden }\end{array}$ & 14 de mayo \\
\hline $\begin{array}{l}\text { Reunión en la Universidad Iberoamericana } \\
\text { con estudiantes de la Anáhuac. Tec de }\end{array}$ & 5 de mayo \\
Monterrey e ITAM & 6 de mayo \\
\hline $\begin{array}{l}\text { Reunión de trabajo de estudiantes en la } \\
\text { Universidad Iberoamericana }\end{array}$ & 7 de mayo \\
\hline $\begin{array}{l}\text { Reunión de trabajo de estudiantes en el } \\
\text { Marque Hundido }\end{array}$ & 7 de mayo \\
\hline $\begin{array}{l}\text { Presentación del código de ética de los } 131 \\
\text { alumnos }\end{array}$ & 8 de mayo \\
\hline $\begin{array}{l}\text { Primera marcha interuniversitaria } \\
\text { Publicación del posicionamiento }\end{array}$ & 23 de mayo \\
\hline $\begin{array}{l}\text { Peunión interuniversitaria (Parque } \\
\text { Publicación de código de ética general }\end{array}$ & 23 de mayo \\
\hline \begin{tabular}{l} 
Publicación del pliego petitorio \\
\hline
\end{tabular} & 27 de mayo \\
\hline mayo
\end{tabular}

I Panorama

I pp. 86-102

I Volumen 9

I Número 17 I Julio-diciembre

Fuente: Modificado de Sierra (2014, pp. 171-176).
I 2015 
José Javier

Capera

Figueroa I

Sergio Alfonso

Huertas

Hernández I

Felipe Gabino

Macedo I

Por esto, desde las ciencias sociales, y específicamente desde la ciencia política, el estudio de los movimientos sociales se ha caracterizado por la teoría de los movimientos sociales estudiada desde la ciencia política, que se articula desde el enfoque de la teoría de la elección racional, que otorga un papel neurálgico al interés individual en búsqueda de su mayor provecho. Los trabajos de Olson (1965) o Tullock (1971) son los mejores botones de muestra (Román Marugán, 2002, p. 21), los cuales intentan realizar un ejercicio sobre los elementos y los factores que están inmersos en la construcción de los movimientos sociales. Por ello, la visión de la elección racional pretende realizar un ejercicio de ventajas y desventajas de la acción política en los movimientos.

En ese sentido, el trayecto histórico que ha desarrollado la ciencia política en su ejercicio de institucionalización responde a abordajes conceptuales sobre temas, como Partidos políticos, formas de gobierno, Democracias, Regímenes políticos y movimientos sociales. Ya en los movimientos sociales se logra identificar que autores, como Lechner (1981), mencionan que la política ya no es lo que fue; en ese sentido, no se puede seguir esperando de ella los grandes proyectos y utopías que en algún momento de la historia la caracterizaron, ni puede pensarse que mediante la política sea posible la construcción de un orden social. La política cobra nuevos significados en los movimientos sociales, que intentan refundar la utopía y apostarle a la construcción de otros mundos posibles (Molina y Caicedo, 2012, p. 214).

Número 17 |

Por consiguiente, se establece a su vez que normalmente el estudio de los movimientos sociales se ha orientado en tres direcciones: (1) hacia el análisis del contexto en que estos emergen, 2) sobre su forma particular de organizarse, actuar y comunicarse y 3) respecto del impacto que estos generan al actuar (Puig, 2010). Teniendo en cuenta estas tres orientaciones, el objetivo del presente artículo consiste en elaborar una reflexión en torno a la segunda dirección, ya que, como lo menciona Puig (2010), el estudio de los movimientos como actor político permite la pretensión de intentar analizar qué tipo de acción colectiva genera, cómo se organizan y qué simbología crean desde el interior para el exterior y recíprocamente. En esta dirección, es posible sintetizar los ángulos de análisis mediante las siguientes preguntas: ¿qué hacen los movimientos sociales? y ¿cómo hacen parte de la organización?

Dentro de esta perspectiva, se presentarán algunas aproximaciones teóricas sobre la literatura de los movimientos sociales, para así realizar un abordaje extenso y poder interpretar las dinámicas del movimiento estudiantil \#YoSoy132. Asimismo delimitar fases, como la emergencia, la consolidación y el fracaso del \#YoSoy132 y su contextualización como actor político y movimiento estudiantil mexicano, con el fin de construir posibles conclusiones sobre la interrelación que tienen los movimientos estudiantiles latinoamericanos en la esfera de los nuevos movimientos sociales, partiendo por establecer los avances de la ciencia política en el análisis de los movimientos de carácter estudiantil, para así generar diatribas en torno al siguiente cuestionamiento: ¿¿cuáles fueron las características que constituyeron los aciertos y desaciertos frente a la conformación del movimiento estudiantil \#YoSoy132?, y con ello llegar a ciertas consideraciones finales respecto del desarrollo teórico construido del movimiento.

\section{MOVIMIENTO ESTUDIANTIL \#YOSOY132 Y LA TEORÍA DE LOS MOVIMIENTOS SOCIALES}

Las grandes transformaciones sociales que se han originado responden a una serie de elementos que gradúan el tiempo y las dinámicas de la sociedad. Por una parte, encontramos una concepción proveniente de la modernidad, en la que se fraguaron ideas políticas, económicas y culturales para así concebir nuevos modos de vida y formas de organización de los territorios, Estados y sociedades, los cuales pudieron dar solución a los problemas estructurales de la época. Una muestra de esto resultaron ser las organizaciones políticas, los grupos de interés y de presión o asociaciones que realizaron un ejercicio de resistencia contra el statu quo del momento. 
Desde esta perspectiva de análisis, se fortalece la construcción de los movimientos sociales, ya que un movimiento social es un sistema de narraciones, al mismo tiempo que un sistema de registros culturales, explicaciones y prescripciones de cómo determinados conflictos son expresados socialmente y de cómo y a través de qué medios la sociedad ha de ser reformada, partiendo de que el orden correcto de la modernidad, que una y otra vez ha sido aplazado y frustrado, debe ser rediseñado (Ibarra y Tejerina, 1998, citado en Román Marugán, 2002).

De esta forma, se logra observar que las nociones de los movimientos sociales también responden a la visión de Igid y Tarrow (1997, p. 21), quien señala que los movimientos sociales son los desafíos colectivos planteados por personas que comparten objetivos comunes y solidaridad en una interacción mantenida con las élites, los oponentes y las autoridades (Román Marugán, 2002, p. $15,16)$.

Al mismo tiempo, la literatura de los movimientos sociales articula actores colectivos de movilizaciones, cuya meta es provocar, impedir o reproducir un cambio social básico. Persiguen estas metas con cierta dosis de continuidad sobre la base de una elevada integración simbólica, una escasa especificación de roles y mediante formas variables de organización y acción (Orjuela et. Al., 2012).

Por ello, las nociones teóricas de los movimientos sociales buscan, desde la óptica de Alberoni (1981), resaltar que las fuerzas impetuosas del movimiento inquieren componer que la institución llegue a estados lacónicos, los cuales puedan, desde la lucha sostenida, dar grandes resultados, para así realizar acciones que solidifiquen los movimientos, las organizaciones y las convenciones formales y de largo tiempo en los Estados.

Por esto, las lógicas analísticas dadas por el profesor Tarrow (1997, p. 148) describen la emergencia de estas voces críticas que se hacen factibles no solo porque existan motivos de queja, sino también porque se abre un conjunto nuevo de oportunidades para la acción, como pueden ser una mayor facilidad de acceso institucional (debido a la fuerza o debilidad del Estado), cambios de alianzas o incluso de naturaleza en el sistema de partidos (actores siempre presentes en la identificación del conflicto político), una situación de conflicto y, por tanto, de división en las elites. Además, Tarrow también recuerda que los movimientos crean oportunidades para sí mismos o para otros, refiriéndose al establecimiento de redes sociales o coaliciones de actores sociales, así como incentivos para que respondan las élites (Román Marugán, 2002, p. 18).

Otro eje de análisis sobre la teoría de los movimientos sociales se encuentra en los aportes epistémicos dados por la corriente del comportamiento colectivo (Rodríguez-Cabello, 1999), donde se establece que los cambios en la sociedad provienen de adentro hacia afuera y que los grupos tienden a mantener unas características de integración al compartir sentimientos, valores e identidades, que ejercen un sentido de pertenencia y solidaridad interna (Tarrow, 2010, p. 245).

Asimismo, el análisis de los movimientos sociales desde la protesta social (Saavedra, 2012) recurre a examinar las dinámicas que incitan a que los movimientos en el caso estudiantil hagan de la protesta social un mecanismo de manifestación e inconformidad hacia la opinión pública, lo cual reafirma el repertorio y la identidad del movimiento en el caso del \# YoSoy132, su amplia afinidad con los escenarios estudiantiles, siendo fundamental en su conformación, organización y demandas que esgrimía el movimiento tanto en su interior como en su exterior. Por ello, hicieron de la protesta social uno de sus principales recursos para convertirse en un agente movilizador de recursos, movilizador de simpatizantes, lo cual conlleva que se genere una legitimidad entre el movimiento y la sociedad civil.

En este sentido, la temporalidad del movimiento \#YoSoy132 en su etapa de emergencia y consolidación estuvo marcada de la siguiente forma (tabla 2):

Tabla 2. Cronograma de consolidación del movimiento \#YoSoy132

\begin{tabular}{ll}
\hline $\begin{array}{l}\text { Segunda reunión interuniversitaria (Plaza de las } \\
\text { Tres Culturas de Tlatelolco) }\end{array}$ & $\begin{array}{l}26 \mathrm{de} \\
\text { mayo }\end{array}$ \\
\hline $\begin{array}{l}\text { Emisión de la convocatoria para observadores } \\
\text { electorales }\end{array}$ & $\begin{array}{l}28 \mathrm{de} \\
\text { mayo }\end{array}$ \\
\hline Primera asamblea general de estudiantes & $\begin{array}{l}30 \mathrm{de} \\
\text { mayo }\end{array}$ \\
\hline Inicia la plataforma \#YoSoy132Media & $\begin{array}{l}6 \mathrm{de} \\
\text { junio }\end{array}$ \\
\hline $\begin{array}{l}\text { Emisión de la convocatoria del \#Debate 132 } \\
\text { Primer debate ciudadano }\end{array}$ & $\begin{array}{l}6 \mathrm{de} \\
\text { junio }\end{array}$ \\
\hline Universidades y Sociedad Civil del 30 de Mayo & $\begin{array}{l}7 \mathrm{de} \\
\text { junio }\end{array}$ \\
\hline
\end{tabular}

I Panorama I pp. 86-102 I Volumen 9 I Número 17 I Julio-diciembre I 2015 


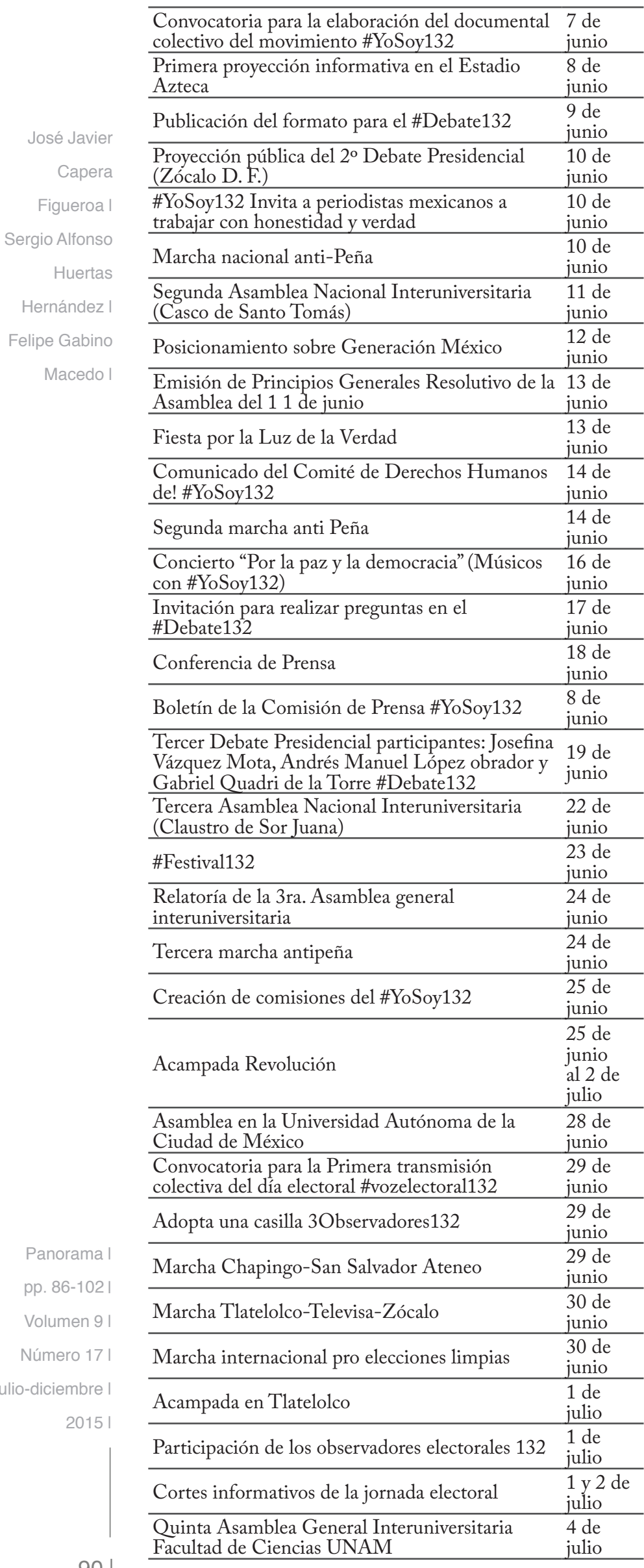

\begin{tabular}{|c|c|}
\hline Acampada revolución 132 & $\begin{array}{l}5 \text { de } \\
\text { julio }\end{array}$ \\
\hline Programa de lucha \#YoSoy132 & $\begin{array}{l}6 \text { de } \\
\text { julio }\end{array}$ \\
\hline $\begin{array}{l}\text { Primer Encuentro Nacional \#YoSoy132. Huexca. } \\
\text { Morelos }\end{array}$ & $\begin{array}{l}67 \text { y } 8 \\
\text { de julio }\end{array}$ \\
\hline $\begin{array}{l}\text { Marcha Informativa Televisa San Ángel-Metro } \\
\text { Universidad-IFE }\end{array}$ & $\begin{array}{l}11 \text { de } \\
\text { julio }\end{array}$ \\
\hline $\begin{array}{l}\text { Sexta Asamblea General Interuniversitaria } \\
\text { ENAH }\end{array}$ & $\begin{array}{l}12 \text { de } \\
\text { julio }\end{array}$ \\
\hline $\begin{array}{l}\text { Convención Nacional contra la imposición en } \\
\text { San Salvador Atenco }\end{array}$ & $\begin{array}{l}14 \text { y } 15 \\
\text { de julio }\end{array}$ \\
\hline $\begin{array}{l}\text { Pronunciamiento Post-electoral de la Asamblea } \\
\text { \#Academicos132 }\end{array}$ & $\begin{array}{l}14 \mathrm{de} \\
\text { julio }\end{array}$ \\
\hline Manual de asambleas del movimiento \#YoSoy132 & $\begin{array}{l}14 \text { de } \\
\text { julio }\end{array}$ \\
\hline $\begin{array}{l}\text { Convocatoria a medios libres y medios } \\
\text { independientes para acciones y lucha. }\end{array}$ & $\begin{array}{l}15 \text { de } \\
\text { julio }\end{array}$ \\
\hline Festival Revolución & $\begin{array}{l}20,21 \\
\text { y } 22 \text { de } \\
\text { julio }\end{array}$ \\
\hline $\begin{array}{l}\text { Segunda Megamarcha contra [a imposición (Los } \\
\text { Pinos-Ángel de la Independencia-Zócalo) }\end{array}$ & $\begin{array}{l}22 \text { de } \\
\text { julio }\end{array}$ \\
\hline $\begin{array}{l}\text { Pronunciamiento del Comité Jurídico y de } \\
\text { Derechos Humanos del Movimiento sobre las } \\
\text { detenciones de la Megamarcha }\end{array}$ & $\begin{array}{l}23 \text { de } \\
\text { julio }\end{array}$ \\
\hline Toma simbólica de Televisa & $\begin{array}{l}24 \text { de } \\
\text { julio }\end{array}$ \\
\hline Noticiero "Al aire libre" $1^{a}$ parte & $\begin{array}{l}25 \text { de } \\
\text { julio }\end{array}$ \\
\hline $\begin{array}{l}\text { "Toma Pacífica a Televisa" Discurso frente a } \\
\text { televisa de\#YoSoy132. }\end{array}$ & $\begin{array}{l}27 \mathrm{de} \\
\text { julio }\end{array}$ \\
\hline Clausura del Cerco a televisa & $\begin{array}{l}28 \text { de } \\
\text { julio }\end{array}$ \\
\hline $\begin{array}{l}\text { Asamblea Nacional Interuniversitaria. Morelia, } \\
\text { Michoacán }\end{array}$ & $\begin{array}{l}28 \text { y } 29 \\
\text { de julio }\end{array}$ \\
\hline $\begin{array}{l}\text { Segundo boletín de prensa de la Asamblea } \\
\text { Nacional Interuniversitaria en Morelia }\end{array}$ & $\begin{array}{l}29 \text { de } \\
\text { julio }\end{array}$ \\
\hline Transmisión en vivo desde acampada revolución & $\begin{array}{l}29 \text { de } \\
\text { julio }\end{array}$ \\
\hline Tercer boletín informativo de la Asamblea & $\begin{array}{l}30 \mathrm{de} \\
\text { julio }\end{array}$ \\
\hline $\begin{array}{l}\text { Conferencia de Prensa. Asamblea } \\
\text { Interuniversitaria }\end{array}$ & $\begin{array}{l}30 \text { de } \\
\text { julio }\end{array}$ \\
\hline $\begin{array}{l}\text { Invitación a la Convención Estatal contra la } \\
\text { Imposición en Chiapas }\end{array}$ & $\begin{array}{l}6 \text { de } \\
\text { agosto }\end{array}$ \\
\hline $\begin{array}{l}\text { \#YoSoy132Salud Brigada de Información y de } \\
\text { Servicios a la Comunidad Zócalo Capitalino }\end{array}$ & $\begin{array}{l}7 \text { de } \\
\text { agosto }\end{array}$ \\
\hline $\begin{array}{l}\text { Convocatoria para la elaboración del } \\
\text { Contrainforme de Gobierno, en ESIME, } \\
\text { Zacatenco }\end{array}$ & $\begin{array}{l}7 \text { de } \\
\text { agosto }\end{array}$ \\
\hline Acampada revolución "Toma pacífica de Televisa" & $\begin{array}{l}7 \text { de } \\
\text { agosto }\end{array}$ \\
\hline
\end{tabular}

Fuente: Modificado de Sierra (2014)

Otro paralelo de gran importancia consiste en indicar, desde de la ciencia política, que los movimientos sociales se localizan en una compleja definición, en la que concierne solo la pretensión de que debe estar organizada en torno a un esquema teórico-analítico paralelo al de la teoría económica, donde la única fórmula actual de pretensión es la que debe ser tratada en la teoría del poder. 
La ciencia política como disciplina a la que concierne el poder analítico, su uso, su control, pero debido a la difusividad del poder político eso la convierte en una ciencia sintética en el campo del sistema social, no es una ciencia constituida en torno a un esquema conceptual analítico distintivo, es decir, a una serie de variables estrictamente limitadas (Parsons, 1999, p. 350).

Para este tipo de análisis, Easton (2006, p.77) ofrece una definición en el sistema político como "aquellas interacciones por medio de las cuales se asignan autoritariamente valores a una sociedad; esto es lo que lo distingue de otros sistemas de su medio". La primera clase comprende aquellos conjuntos de variables, actitudes, ideales y conductas, tales como economía, cultura, estructura social y personalidades individuales, que son sistemas ambientales o paramétricos que pertenecen a la sociedad misma y al sistema político, pero que, al no asignar autoritariamente valores, no son sistemas políticos, sino que se constituyen como componentes del sistema político, que ejercen cierta influencia en la forma de operar del sistema político. En otras palabras, un ambiente intra-social está por fuera de los límites del sistema político, pero dentro de la sociedad donde este se encuentra.

Asimismo, la psicología "en cuanto disciplina analítica, puede definirse aquí como la ciencia a la que conciernen los procesos elementales de la acción y su organización en personalidades como sistemas" (Parsons, 1999, p.166); (Javaloy, Carballeira y Espelt, 2001). Estas concepciones del comportamiento colectivo son formuladas por la ciencia política a partir del análisis conductista, el cual se centra en una única pregunta, engañosamente simple: ¿por qué la gente se comporta como lo hace? Lo que diferencia el conductismo de otras disciplinas de las ciencias sociales es 1) su insistencia en el comportamiento observable, ya sea a un nivel individual, ya sea de agregado social, que debe ser el centro del análisis, y 2) que cualquier explicación debe poder someterse a una comprobación empírica (Marsh y Stoker, 1997, p. 69).

Ahora bien, desde la perspectiva de la construcción social, los movimientos aparecen como agencias de significación colectiva con capacidad para la difusión de nuevas ideas en la sociedad, y para producir marcos de referencia a partir de los que sus seguidores interpretan los fenómenos sociales; y para la teoría del proceso político, los movimientos sociales son formas de comportamiento organizado y racional, causa principal de algunas de las transformaciones más importantes en sociedades actuales (Román Marugán, 2002, p. 20).

Igualmente, la característica de que no existen modelos únicos de organización sobre los movimientos, como lo sostienen Marwell y Oliver (1988), señalando que la heterogeneidad y la interdependencia son los mejores acicates para la acción colectiva que la homogeneidad y la disciplina (Tarrow, 1997, citado en Román Marugán, 2002).

A su vez, existe una mirada conceptual que versa sobre aspectos, como las motivaciones por participar activamente en los asuntos públicos, la visión de trasformación social y el carácter reivindicativo de las condiciones históricas del momento, siendo estos insumos para gestar procesos en el interior de consignas y emblemas que intentan generar rupturas en las estructuras del Estado y las acciones gubernamentales.

Del mismo modo, encontramos que la perspectiva que constituye los movimientos sociales se haya inmersa en un cliché, el cual busca interrelacionar la acción colectiva con la acción política, con el fin de realizar una simbiosis que instituye la concepción del movimiento en determinadas circunstancias. Es decir que en las décadas de 1980 y 1990, los movimientos sociales desplegaron una serie de repertorios en forma de acciones colectivas que movilizaron profundamente a la sociedad desde su base social. Sus demandas y acciones se enfrentaron, de forma reiterada, a los sistemas económicos (Jácome, 2010, p. 101).

Otro fenómeno resultó ser el caso de la proliferación de los movimientos sociales que se gestaron en América Latina, los cuales plantearon nuevas formas de expresión frente a sus luchas y prontuarios simbólicos y sociales. Es el caso de la constitución de los discursos en las acciones colectivas de los movimientos que identificaron problemas que ameritaban luchas sociales y políticas, como la tierra, el ambiente, los derechos y la igualdad de las mujeres, la vivienda, el reconocimiento de las identidades, la educación y la participación. Entre todos ellos, el movimiento indígena, en la década de 1990, logró expresar sus demandas sobre el reconocimiento de la identidad y de la redistribución de los recursos respecto de la justicia integral. Ejemplo de esto fue el movimiento indígena boliviano, ecuatoriano
| Características constituyentes de los aciertos y desaciertos frente a la conformación del movimiento estudiantil \#YoSoy132 
José Javier

Capera

Figueroa I

Sergio Alfonso

Huertas

Hernández I

Felipe Gabino

Macedo I

El estudio de la categoría de movimiento social responde en gran parte al reemplazo conceptual de clases, ya que, con la decadencia en la década de 1960 de las vanguardias, se queda obsoleto hacer referencia a la lucha de clases. De esto se originan dimensiones que abarcan la concepción de movimientos sociales, tales como la dimensión política, cultural, social, étnica, religiosa, entre otras, tras lo cual dejan en escena la perspectiva de análisis sobre los movimientos sociales que se mueven en una tensión entre el análisis de la estrategia y el de la identidad (Pont Vidal 1998).

Para entender la acción colectiva, en unos casos se han privilegiado formas más pragmáticas, tales como los costos y beneficios que los movilizados (no los actores) pueden obtener de su despliegue de tácticas y estrategias (McAdam, McCarthy y Zald, 1996). Al mismo tiempo, los repertorios de acción colectiva (Tilly, 1998) de los movimientos sociales son creaciones culturales aprendidas que emergen de la lucha, de las interacciones entre los ciudadanos y el Estado (Jácome, 2010, p. 104).

Desde otra perspectiva, los movimientos sociales son la expresión de un conflicto estructural, por intereses contrapuestos sobre el control de los instrumentos de la producción de la vida social. Según este planteamiento, para que un movimiento social realmente sea tal debe haber una interrelación entre tres condiciones: la definición de la identidad del actor, la definición del oponente y el campo del conflicto (Touraine, 1985, citado en Jácome, 2010).

Por otro lado, los aportes construidos por el filósofo moderno Habermas (1985) hacen alusión a la diferencia entre los movimientos sociales potenciales emancipatorios y los que buscan hacer resistencia y repliegue. En efecto, la colonización del mundo de la vida provoca la formación de nuevas formas de protesta social, que dirigen necesidades simbólicas antes que instrumentales.

En una vertiente bastante similar descrita por Castells (2011), diferencia tres formas de construcción de la identidad: identidad legitimada que racionaliza la dominación, identidad de resistencia relacionada con quienes construyen trincheras de resistencia e identidad de proyecto, según la cual actores sociales sobre la base de materiales culturales construyen una nueva identidad que redefine su posición en la sociedad, en busca de transformar la estructura social. La primera forma daría lugar a la sociedad civil, la segunda daría como consecuencia la construcción de comunidades, mientras que la tercera daría lugar a la construcción de sujetos sociales (Jácome, 2010, p. 104).

Para los contextos de América Latina, aparecen elementos que relacionan los movimientos sociales con aspectos que adquieren gran relevancia debido a las dimensiones de la política (acción) y lo político (proceso), donde se resaltan los estudios realizados por Laclau y Mouffe (2004), y se discute el conjunto de luchas diversas: urbanas, ecológicas, antiautoritarias, antiinstitucionales, feministas, antirracistas, pro minorías étnicas, regionales o sexuales. Son acciones integradoras de los movimientos sociales que contribuyen a que los límites entre estas luchas frecuentemente sean indistinguibles (Escobar, 1992). Para los teóricos latinoamericanos, las cuestiones de estrategia y de identidad de los movimientos sociales están inextricablemente vinculadas: son algo exterior al Estado, y si bien es cierto que aquel es su principal interlocutor, esto no puede ser reducido a la lógica gubernamental o instrumental (Jácome, 2010, p. 106).

Sobre el fracaso de los movimientos sociales, (Escobar 1992) propone una forma más fluida de valorarlos, en términos de poder: ¿qué formas de poder (estatal, de género, económico, etc.) son socavadas?, ¿qué tipos de libertades se obtienen de la relación con el Estado? y, a la inversa, ¿qué se extrae del movimiento en tal relación?, ¿qué formas de poder popular son fortalecidas por el movimiento?; es decir, la valoración tiene que considerar esta relación compleja entre el Estado y la sociedad.

De igual manera, los aportes sustanciales elaborados por el sociólogo Fals Borda (1992) plantean que los movimientos sociales son capaces de construir un nuevo ethos, destinados a concebir una apuesta a mejorar la sociedad y las relaciones sociales en las cuales la unidad pueda coexistir con la diversidad. Los movimientos sociales y populares más avanzados favorecen la negociación, el diálogo y las soluciones razonables para conflictos existentes. 
Ya en la década de 1990 hubo un pico alto de movilización colectiva, en aquel momento (al parecer) las diferentes vertientes de los movimientos sociales no estarían tan activas. Sin embargo, para este proyecto político, la sociedad del buen vivir solo se puede construir en la medida en que exista participación activa de las organizaciones y movimientos sociales. Pero este reconocimiento debe ser por partida doble: es decir, los actores sociales deben tener una lectura de la oportunidad política actual (Jácome, 2010, p. 109).

Gran parte de la contribución teórica, que se relaciona con el estudio de los movimientos sociales, se enfoca en la emergencia del constructo de los discursos provenientes de las dinámicas sociales, políticas y culturales. Respondiendo en primera instancia a las acepciones epistemológicas que se concibieron en la sociología, con el paso de los años el estudio de la sociología política incorpora en sus constructos las tendencias de discutir las teorías de los movimientos sociales como producto de los lazos colectivos, las asociaciones y las relaciones sociales, asimismo las acciones colectivas, que genera una serie de clivajes históricos con una extensa mirada de transformaciones políticas.

Es necesario, por ello, señalar que los movimientos sociales (Escobar, 1992) han logrado no solo transformar en algunas instancias sus agendas políticas en políticas públicas y expandir las fronteras de la política institucional, sino que también han luchado por otorgar nuevos significados a las nociones heredadas de ciudadanía, representación y participación política y, como consecuencia, de la propia democracia.

Ahora bien, el entorno social alcanza su unidad solo mediante el sistema político y en relación con el sistema, asimismo existe una complejidad en los movimientos frente a estos factores, porque se podrían ubicar en el entorno social bajo una atribución externa, lo cual no quiere decir que el entorno dependa del sistema o en caso contrario que el sistema tenga a su entera disposición el entorno. Pero esto no disocia la relación de dependencia en la que se encuentran sujetos tanto en el entorno como en el sistema social a la hora de ser objeto de análisis de los movimientos sociales. La única salvedad que se puede identificar es que los sistemas políticos de cierta manera corresponden al entorno social como unidad que se constituye bajo el mismo elemento.
Esto lleva a pensar una diferenciación que tiene en cuenta la relación entre el entorno y el sistema, que conlleva la plena identificación de que

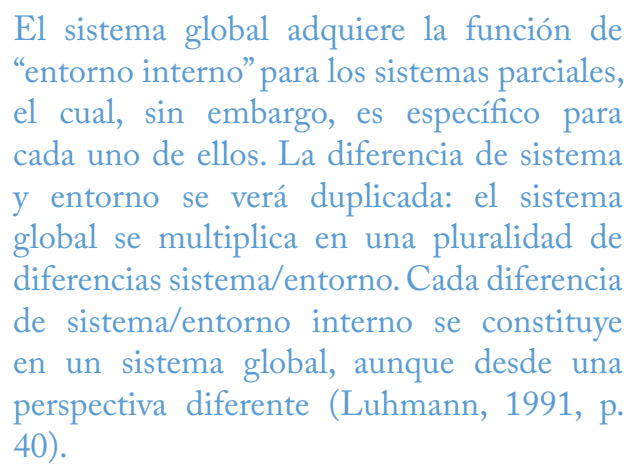

Desde esta mirada, es comprensible que tanto la sociología como la ciencia política tienen aproximaciones teóricas y epistemológicas en torno a la concepción de los movimientos sociales, una respecto de los sistemas ( la sociología) y otra respecto del entorno (la ciencia política), pero cada una de estas dos constituyen un sistema global de análisis que se complementa.

En los procesos contemporáneos en los que se evidencia una serie de dinámicas que ponen en tela de discusión el estudio de los movimientos sociales, se gesta la comprensión de lo anteriormente señalado, mostrándose de esta manera que la politología sustituida por la sociología es una dicotomía entre lo social y lo político (Prélot 2002), que hace la distinción de los estudios politológicos y los sociológicos de esta manera:

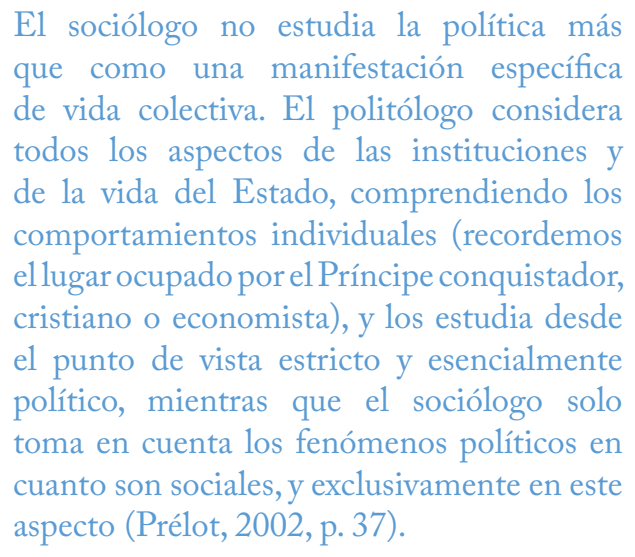

En efecto, se debe señalar que la investigación de los movimientos sociales, como campo de investigación de la ciencia política, apenas ha empezado, remontándose, en el mejor de los casos, a principios de la década de 1990. Veinte años después del proceso de instauración del sistema político democrático, si hacemos un "balance" de la investigación de los movimientos sociales y de los
Características

constituyentes

de los aciertos

y desaciertos

frente a la

conformación

del movimiento

estudiantil

\#YoSoy132
I Panorama

I pp. 86-102

I Volumen 9

I Número 17

I Julio-diciembre

I 2015 
José Javier

Capera

Figueroa I

Sergio Alfonso

Huertas

Hernández I

Felipe Gabino

Macedo I

Panorama I

pp. 86-102।

Volumen 91

Número 17 |

Julio-diciembre |

2015 |

La politización, por tanto, implica una pérdida de la importancia del enfoque basado en un poder central; significa que los procesos que hasta ahora siempre habían discurrido sin fricciones se extinguen frente a la resistencia de objetivos contradictorios (Beck, Lash y Giddens, 1997, p. 39).

Desde esta perspectiva de la subpolítica, autores, como De Soussa Santos (2001), sostienen cómo la distinción y el trayecto de los nuevos movimientos sociales con el Estado es más aparente que real, pues las reivindicaciones globales-locales siempre acaban por traducirse en una exigencia hecha al Estado y en los términos en que este se sienta ante la contingencia política de tener que darle respuesta, además, la prueba de eso es que no es raro que los nuevos movimientos sociales jueguen el juego de la democracia representativa, aunque sea por el lobby y por la vía extraparlamentaria, que entran en alianzas más o menos oficiales con sindicatos y partidos, cuando ellos mismos no se transforman en partidos.

Estos aspectos de los movimientos sociales son los que rescatan y estudian la ciencia política, ya que están inmersos no solo desde los contextos latinoamericanos, sino que están convulsionando la forma de analizar las perspectivas y tradiciones de los movimientos sociales en Estados Unidos y Europa.

En este momento, se evidencia que uno de los principales enfoques con los que se llevan a cabo estos análisis sobre los movimientos sociales desde la ciencia política es el behaviorismo, cuyo enfoque Vera (2005) sintetiza en seis puntos:

1. Existen regularidades en el comportamiento humano que pueden ser descubiertas.

2. Estas regularidades pueden ser confirmadas por pruebas empíricas.

3. Rigor metodológico para la recopilación de datos y su análisis. La cuantificación adquirió un papel central en la disciplina.

4. Cambios de rol de la teoría: la teoría behaviorista está orientada empíricamente. Busca cómo explicar, comprender y, si es posible, predecir el comportamiento político de los seres humanos y el funcionamiento de las instituciones políticas o los movimientos sociales.

5. Separación de hechos y valores: el behaviorismo asumió las tesis positivistas del Círculo de Viena sobre la posibilidad de una investigación libre de valores.

6. Defensa de la ciencia pura frente a la investigación aplicada: la tarea fundamental del científico social era la comprensión y explicación. Solo después de 
la obtención de un conocimiento exacto de cómo funcionan las instituciones políticas y cómo se comportan políticamente los seres humanos sería posible aplicar este conocimiento para la solución de problemas (p. 29,31).

De esta forma, los movimientos sociales se articulan a múltiples finalidades en su pensamiento, contexto, orígenes, y varían según las culturas, las regiones y países. Debido a su carácter polifónico o, en el mejor de los casos, a las estratégicas políticas que se utilizan para construir procesos donde la desobediencias civiles, las resistencias o la subpolítica estén presentes en los escenarios en los que las discusiones discurren a los campos asociados a las transformaciones sociales o reformulaciones coyunturales de las instituciones.

Respondiendo a fenómenos complejos, cuyo estudio desde la ciencia política no es de tan larga duración, la rigurosidad científica debe tener en cuenta dichos factores y establecer las fronteras entre ellos y otras formas de acción política, como lo menciona Pérez Ledesma (1994) al señalar que existen periodos históricos en los que los movimientos sociales deben ser explicados como acciones colectivas que se caracterizan por su larga duración y sus impactos reformistas en ciertos casos de los regímenes políticos.

Por esto el movimiento \#YoSoy132 se articula con las interacciones provenientes de los nuevos movimientos sociales, puesto que en su organización la distinción moderna de clases ha sido superada, las disputas ideológicas son temas del ayer, pero, en especial, la búsqueda de sectores para enfrentar a un "posible" adversario se encuentra en construcción. Debido a estos elementos, uno de los desaciertos del movimiento fue su fraguada y poca canalización de las fuerzas, las demandas y los objetivos frente a la crisis del Estado mexicano.

Por otro lado, los principales asuntos del movimiento \#YoSoy132 se encuentran sintetizados en el plan de lucha que posee elementos que logran vislumbrar de manera analítica su conformación en el interior, su posible forma de "organización", pero, en especial, las acciones que van en función de su identidad; por ello, en el plan de lucha se constatan propuestas, como:

1. La democratización y transformación de los medios de comunicación, información y difusión, lo cual va en contravía de toda la estructura del poder político del momento.
2. El cambio de modelo educativo, científico y tecnológico.

3. El cambio en el modelo económico neoliberal.

4. El cambio en el modelo de seguridad nacional y justicia.

5. La transformación política y vinculación con movimientos sociales.

6. Los cambios en materia de salud. Así es como para julio de 2012 el movimiento asumió actividades como las que se describen en la tabla 4.

Tabla 4. Actividades movimiento \#YoSoy132

\begin{tabular}{|c|c|}
\hline $\begin{array}{l}\text { Convención Estatal Contra la Imposición } \\
\text { en Chiapas }\end{array}$ & 8 de agosto \\
\hline Marcha anti-imposición & 8 de agosto \\
\hline $\begin{array}{l}\text { \#YoSoy132SALUD: Brigada de } \\
\text { información y servicios a la comunidad }\end{array}$ & 8 de agosto \\
\hline $\begin{array}{l}\text { Contra Informe de Gobierno, III Informe } \\
\text { Fernando Ortega Bernes }\end{array}$ & 8 de agosto \\
\hline $\begin{array}{l}\text { Síntesis de Informe General de Delitos } \\
\text { Electorales de la Comisión de Vigilancia } \\
\text { Ciudadana (General report on electoral } \\
\text { irregularities and offenses registered by the } \\
\text { Citizen Surveillance Comittee \#YoSoy132) }\end{array}$ & 8 de agosto \\
\hline $\begin{array}{l}\text { Campaña gráfica homenaje a Zapata } \\
\text { (Frente Gráfico) }\end{array}$ & 8 de agosto \\
\hline $\begin{array}{l}\text { Antología Literaria }-132+1 \text { aniversario del } \\
\text { natalicio de Emiliano Zapata }\end{array}$ & 8 de agosto \\
\hline $\begin{array}{l}\text { Carta en Solidaridad con Chile Asamblea } \\
\text { Local \#YoSoy132 UAM Cuajimalpa }\end{array}$ & 9 de agosto \\
\hline $\begin{array}{l}\text { Convocatoria a la Megamarcha contra la } \\
\text { Imposición }\end{array}$ & 9 de agosto \\
\hline Megamarcha contra la Imposición & 11 de agosto \\
\hline Lectura masiva en las instalaciones del PRI & 11 de agosto \\
\hline $\begin{array}{l}\text { Minuta de la Reunión de la Coordinadora } \\
\text { Provisional para la } 2^{\text {a }} \text {. Convención } \\
\text { Nacional contra la Imposición }\end{array}$ & 12 de agosto \\
\hline \#Quieroparamexico Twitter en la calle & 12 de agosto \\
\hline $\begin{array}{l}\text { Minuta de la Reunión para el } \\
\text { Contrainforme de Gobierno }\end{array}$ & 14 de agosto \\
\hline $\begin{array}{l}\text { Convocatoria "Nueva Constitución" por la } \\
\text { Asamblea Másde131 }\end{array}$ & 15 de agosto \\
\hline $\begin{array}{l}\text { Concurso de Fotografía \#YoSoy132 } \\
\text { Internacional }\end{array}$ & 15 de agosto \\
\hline $\begin{array}{l}\text { VIII Asamblea General Interuniversitaria, } \\
\text { Facultad de Ciencias Políticas y Sociales } \\
\text { UNAM }\end{array}$ & 13 de agosto \\
\hline $\begin{array}{l}\text { 1er. Boletín de Prensa 8va Asamblea } \\
\text { General Interuniversitaria }\end{array}$ & 20 de agosto \\
\hline $\begin{array}{l}\text { 2do, Boletín de prensa 8va Asamblea } \\
\text { General interuniversitaria }\end{array}$ & 20 de agosto \\
\hline $\begin{array}{l}\text { 1er. Encuentro metropolitano de } \\
\text { académicos }\end{array}$ & 22 de agosto \\
\hline Encuentro Estatal \#YoSoy132Gxaca & 22 de agosto \\
\hline
\end{tabular}

I Panorama

I pp. 86-102

I Volumen 9

I Número 17 


\begin{tabular}{|c|c|c|}
\hline & $\begin{array}{l}\text { Taller Nacional de Derechos Humanos y } \\
\text { Seguridad Ciudadana para Integrantes de } \\
\text { \#YoSoy132 }\end{array}$ & $\begin{array}{l}23,24 \text { y } 25 \text { de } \\
\text { agosto }\end{array}$ \\
\hline José Javier & $\begin{array}{l}\text { Brigadeo\#Alerta132, Carta al Pueblo de } \\
\text { México }\end{array}$ & 24 de agosto \\
\hline Capera & $\begin{array}{l}\text { VII Asamblea Internacional } \\
\text { \#YoSoy132lnternacional }\end{array}$ & 26 de agosto \\
\hline Figueroa I & $\begin{array}{l}\text { VIH Asamblea Virtual } \\
\text { \#YoSoy132lnternacional }\end{array}$ & 30 de agosto \\
\hline $\begin{array}{r}\text { Sergio Alfonso } \\
\text { Huertas }\end{array}$ & $\begin{array}{l}\text { IX Asamblea General Interuniversitaria, } \\
\text { Saltillo. Coahuila }\end{array}$ & 30 de agosto \\
\hline Hernández I & $\begin{array}{l}\text { Movilización \#QuéDemocraciaEsEsta } \\
\text { (cacerolazo frente al TEPJF) }\end{array}$ & 30 de agosto \\
\hline $\begin{array}{l}\text { Felipe Gabino } \\
\text { Macedo I }\end{array}$ & $\begin{array}{l}\text { Toma de casetas México-Querétaro, } \\
\text { México-Puebla y México-Cuernavaca } \\
\text { por la inconformidad de la resolución del } \\
\text { TEPJF }\end{array}$ & 31 de agosto \\
\hline
\end{tabular}

Relatoría de detenciones arbitrarias,

hostigamientos, golpes y abusos de autoridad a

estudiantes de la Asamblea \#YoSoy132

31 de agosto

de la Facultad de Filosofía y letras de la UNAM

\begin{tabular}{|c|c|}
\hline $\begin{array}{l}\text { Marcha fúnebre por la democracia } \\
\text { \#YoSoy132 }\end{array}$ & 31 de agosto \\
\hline \#Contrainforme132 & $\begin{array}{l}2 \text { de } \\
\text { septiembre }\end{array}$ \\
\hline $\begin{array}{l}\text { Contrainforme Estatal de Veracruz Toma } \\
\text { pacífica del Palacio Municipal de Xalapa y } \\
\text { del puerto de Veracruz }\end{array}$ & $\begin{array}{l}2 \text { de } \\
\text { septiembre }\end{array}$ \\
\hline $\begin{array}{l}\text { Posicionamiento político de \#YoSoy132 } \\
\text { ante el fallo del TEPJF }\end{array}$ & $\begin{array}{l}2 \text { de } \\
\text { septiembre }\end{array}$ \\
\hline Foros \#Contrainforme132 & $\begin{array}{l}3 \text { de } \\
\text { septiembre }\end{array}$ \\
\hline $\begin{array}{l}\text { Comunicado del Comité Jurídico y de } \\
\text { Derechos Humanos sobre agresiones y } \\
\text { violaciones a los }\end{array}$ & $\begin{array}{l}4 \text { de } \\
\text { septiembre }\end{array}$ \\
\hline $\begin{array}{l}\text { Modelo organizativo de las Asambleas } \\
\text { locales dictado por [a Comisión } \\
\text { Emergente de Organización }\end{array}$ & $\begin{array}{l}6 \text { de } \\
\text { septiembre }\end{array}$ \\
\hline $\begin{array}{l}\text { Represión durante el desalojo de } \\
\text { campamentos en el Zócalo }\end{array}$ & $\begin{array}{l}13 \text { de } \\
\text { septiembre }\end{array}$ \\
\hline $\begin{array}{l}\text { Convocatorias para el } 15 \text { de septiembre } \\
\text { ¡Viva México, sin PRI! }\end{array}$ & $\begin{array}{l}13 \text { de } \\
\text { septiembre }\end{array}$ \\
\hline $\begin{array}{l}\text { Relatoría y rueda de prensa sobre el } \\
\text { desalojo deBomberos y Activistas en el } \\
\text { Zócalo }\end{array}$ & $\begin{array}{l}14 \mathrm{de} \\
\text { septiembre }\end{array}$ \\
\hline Grito alternativo \#YoSoy132 Zócalo D.F. & $\begin{array}{l}15 \text { de } \\
\text { septiembre }\end{array}$ \\
\hline $\begin{array}{l}\text { Protesta en la XI semana Nacional de } \\
\text { Transparencia }\end{array}$ & $\begin{array}{l}19 \text { de } \\
\text { septiembre }\end{array}$ \\
\hline $\begin{array}{l}\text { Presentación del Grupo de } \\
\text { Democratización de los Medios de } \\
\text { Comunicación }\end{array}$ & $\begin{array}{l}19 \mathrm{de} \\
\text { septiembre }\end{array}$ \\
\hline $\begin{array}{l}\text { Comunicado de prensa y a [as } \\
\text { organizaciones de la Segunda Convención } \\
\text { Nacional Contra la Imposición }\end{array}$ & $\begin{array}{l}21 \mathrm{de} \\
\text { septiembre }\end{array}$ \\
\hline $\begin{array}{l}\text { Segunda Convención Nacional Contra la } \\
\text { Imposición }\end{array}$ & $\begin{array}{l}22 \text { de } \\
\text { septiembre }\end{array}$ \\
\hline
\end{tabular}

\begin{tabular}{ll}
\hline $\begin{array}{l}\text { Plan de acción de la Segunda Convención } \\
\text { Nacional contra la Imposición }\end{array}$ & $\begin{array}{l}25 \text { de } \\
\text { septiembre }\end{array}$ \\
\hline $\begin{array}{l}\text { 3er. Comunicado de la Asamblea } \\
\text { \#YoSoy132lnternacional }\end{array}$ & $\begin{array}{l}25 \text { de } \\
\text { septiembre }\end{array}$ \\
\hline Creación del Frente Único & $\begin{array}{l}26 \text { de } \\
\text { septiembre }\end{array}$ \\
\hline Festival \#YoSoy1968 & $\begin{array}{l}30 \text { de } \\
\text { septiembre }\end{array}$ \\
\hline Marcha Zócalo-Tlatelolco \#YoSoy68 & 2 de octubre \\
\hline
\end{tabular}

Fuente: Modificado de Sierra (2014).

En estas se logran identificar las denuncias desarrolladas por parte del movimiento, para así construir una correlación de fuerzas entre el sistema (aparato institucional) y la sociedad civil ("representada" por el \#YoSoy132). Aspectos como la lucha política, los pliegos petitorios con una mirada informativa, la disputa entre actores nacionales y transnacionales son elementos que se encuentran en medio de la tensión del sistema societal (Luhmann, 1998).

En este sentido, los argumentos que versan sobre reconocer que los movimientos estudiantiles poseen características, como su organización ideológica, el fuerte arraigo a las estructuras universitarias y las formas de manifestarse en las sociedad civil para así construir una posible orientación política en la medida en que exis$\tan$ aspectos que cuestionen, demanden, reaccionen y manifiesten desde sus propios recursos y condiciones la disparidad con el Estado, las estructuras de poder y las grandes organizaciones gremiales que imponen un orden sociopolítico en un determinado territorio.

Por este motivo, el movimiento estudiantil es el único movimiento que no tiene una existencia duradera como tal, aunque el movimiento feminista ha declinado casi en todas partes en sus formas originales. Los movimientos ambientales y por la paz están aún más vivos (Klandermans y Tarrow, 1988, citado en Aranda, 2000, p. 236).

En síntesis, a través de la literatura de los movimientos sociales encontramos que el movimiento estudiantil \#YoSoy132 se articula con las categorías de teóricos, como Melucci (2012), Tarrow (2012) y Mouffe (2013), entre otros, debido a que en su conformación en aspectos como el conflicto, las acciones colectivas y el uso de escenarios inmersos en lo político y la política eran latentes, lo cual deja a la luz que en el periodo de 
emergencia del movimiento y en su fase de clímax se presencia una fuerte interrelación con las teorías de los movimientos sociales en su conformación y en el desarrollo de sus acciones entre dos planos la sociedad civil y el Estado mexicano.

\section{MOVIMIENTO ESTUDIANTIL \#YOSOY132 EN MEDIO DE ACIERTOS Y DESACIERTOS}

Una de las grandes críticas presentes en la conformación del movimiento \#YoSoy132 consiste en su precaria organización y la débil canalización de sus demandas, convirtiéndose así en uno de sus desaciertos, lo cual desde su origen se convirtió en la falla que en el interior del movimiento hizo que se generara una disgregación con el paso del tiempo.

La fuerte disputa por el poder, el problema de la "representación" y la toma de vocería frente a la opinión pública hicieron en el movimiento una gran fisura que lo llevó a descomponerse con el tiempo, por ello, el segundo desacierto se encuentra en su falta de coherencia entre el discurso y la práctica (Estrada, 1995), puesto que en medio de la coyuntura se involucran otros actores, como los partidos políticos de "izquierda", los sindicatos de maestros, obreros, electricistas, lo cuanl hizo que el movimiento tomara una posición crítica y propositiva frente a esta ola de asociaciones y acciones contra la imposición de Enrique Peña Nieto como uno de los principales adversarios.

Así es como el movimiento \#YoSoy132 se encontraba en un punto álgido de su estructuración. Muestra de ello se encuentra en el tiempo y la continuidad del movimiento, tal como se evidencia en la cronología que muestra los avances, retrocesos, puntos elevados, declives que este vivió.

En este caso, se puede comprender que las estrategias, los objetivos y la pertenencia del movimiento son elementos que no estuvieron claramente definidos y, por tanto, su espectro estuvo siempre disperso (Candón-Mena, 2013), lo cual dejó dudas en torno a dos ejes funcionales que constituyen la estructuración del \#YoSoy132:

1. El primero, la poca afinidad entre los objetivos y la organización que fueron aspectos funcionales a la lógica interna de \#YoSoy132, lo cual generó un desacierto del movimiento en su configuración.
2. El segundo, la falta de comunicación en los aspectos políticos, organizacionales y el repertorio de estrategias para hacer del movimiento un sujeto de enunciación cargado de una visión detalla y crítica de su contexto (realidad) de aquel entonces, exponiendo así la fragilidad en las bases de edificación del \#YoSoy132, la cual se tradujo en diversos desaciertos:

A. El poco conocimiento del discurso y la práctica, lo cual mostró una fuerte incoherencia desde sus orígenes hasta el estallido del 1 de diciembre de 2012, puesto que las metas del movimiento que estaban incluidas en su plan de lucha se fueron disolviendo hasta llegar a un crisis contundente.

B. La carencia de una sincronización entre el espacio, el tiempo y los escenarios por los cuales transitaban los militantes del \#YoSoy132, características que dejan en crisis la construcción del movimiento social y específicamente de un movimiento estudiantil.

C. La incapacidad de hacer valer su recursos y su figura como un agente movilizador, lo cual se combinaba con la fragilidad frente a las formas de obtención y movilización de recursos del \#YoSoy132, observada en eventos entre distintas universidades y organizaciones sociales; igualmente se presencia una lógica difuminada entre la razón de ser del movimiento y su condicionalidad para ser plataforma política de un "partido político" o de posibles líderes "populistas".

D. La debilidad por canalizar las oportunidades políticas, el escenario internacional y la legitimidad de la ciudadanía, grandes problemas estructurales en la configuración del movimiento, sumando a ello la falta de herramientas para construir procesos endógenos y exógenos del \#YoSoy132 con proyección nacional que creara así redes de comunicación y discursos sólidos para resistir la represión, violencia y acción criminal del Estado.

Por otro lado, entre los aciertos del movimiento \#YoSoy132, encontramos los siguientes:

El primer acierto fue la reivindicación social de aquel entonces, motivo que originó parte de la legitimidad del movimiento hacia la ciudadanía.

El segundo acierto se encuentra en los repertorios que utilizaron los integrantes para darse a conocer como "unidad", unidad marcada por la pacificación, la innovación y la fuerte solidaridad entre los jóvenes universitarios.

El tercero se encuentra en hacer de las tecnologías de la información y de la comunicación un dispositivo de cohesión, difusión y ampliación social, el cual tomó riendas positivas para informar y contrarrestar la
Características constituyentes de los aciertos y desaciertos frente a la conformación del movimiento estudiantil \#YoSoy132 
José Javier

Capera

Figueroa I

Sergio Alfonso

Huertas

Hernández I

Felipe Gabino

Macedo I

El cuarto se halla en las expectativas del movimiento y su plan de lucha, plan que reunía algunas de las demandas y problemáticas de la sociedad mexicana, pero que también respondía a la crisis democrática, electoral y política del momento; motivos que impulsaron las acciones del \#YoSoy132, y aumentaron su fuerza como agente movilizador de simpatizantes y recursos de resistencia política.

El quinto, y posiblemente el acierto más importante, es que se mostró como un movimiento con legítimas reivindicaciones sociales, políticas y culturales, aspectos que sumaban el espectro de inconformidad del movimiento y la ciudadanía, haciendo así que el \#YoSoy132 buscara mecanismos, estrategias y acciones para consolidarse y proyectarse como un estructura sólida y con amplio sentido y legitimidad nacional e internacional.

Así es como la muestra de los vaivenes se encuentra en los procesos históricos del movimiento, cuando se genera la disputa política y económica en el interior de la organización social (tabla 5).

Tabla 5. Cronograma de la disputa política y económica

\begin{tabular}{|c|c|}
\hline $\begin{array}{l}\text { Foro Sentimientos de la Nación. Más de } \\
131\end{array}$ & 25 de octubre \\
\hline $\begin{array}{l}\text { Segunda Asamblea del Frente de Unidad } \\
\text { Revolucionaria (Monumento a la } \\
\text { Revolución) }\end{array}$ & $\begin{array}{l}29 \text { y } 30 \text { de } \\
\text { octubre }\end{array}$ \\
\hline $\begin{array}{l}\text { Invitación a todas las Células \#YoSoy132 } \\
\text { Nacionales e Internacionales a compartir } \\
\text { sus experiencias mediante la publicación de } \\
\text { un video. }\end{array}$ & 30 de octubre \\
\hline 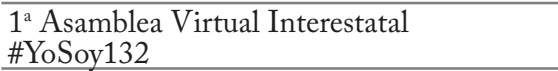 & 31 de octubre \\
\hline $\begin{array}{l}\text { \#YoSoy132 Asamblea metropolitana } \\
\text { (Auditorio de la sección } 9 \text { del CNTE) }\end{array}$ & $\begin{array}{l}3 \mathrm{de} \\
\text { noviem }\end{array}$ \\
\hline $\begin{array}{l}\text { Marcha- caravana por la educación pública } \\
\text { UACM }\end{array}$ & $\begin{array}{l}5 \text { de } \\
\text { noviembre }\end{array}$ \\
\hline $\begin{array}{l}\text { Tercera Reunión de Mesas de Trabajo } \\
\text { \#YoSoy132 }\end{array}$ & \\
\hline $\begin{array}{l}\text { Documento de exigencias mínimas } \\
\text { presentando por la mesa de } \\
\text { Democratización de Medios }\end{array}$ & $\begin{array}{l}7 \text { de } \\
\text { noviembre }\end{array}$ \\
\hline $\begin{array}{l}\text { Fiesta por la \#LuzEnMedios (Cámara de } \\
\text { Senadores) }\end{array}$ & $\begin{array}{l}8 \mathrm{de} \\
\text { novien }\end{array}$ \\
\hline $\begin{array}{l}\text { \#YoSoy132 exige entrada al Congreso de } \\
\text { la Unión }\end{array}$ & $\begin{array}{l}9 \text { de } \\
\text { noviembr }\end{array}$ \\
\hline
\end{tabular}

\begin{tabular}{|c|c|}
\hline $\begin{array}{l}\text { Primera emisión en Radio de } \\
\text { \#YoSoy132Media por 102.1 FM }\end{array}$ & $\begin{array}{l}12 \text { de } \\
\text { noviembre }\end{array}$ \\
\hline Toma de Torniquetes del metro \#YoSoy132 & $\begin{array}{l}13 \text { de } \\
\text { noviembre }\end{array}$ \\
\hline $\begin{array}{l}1^{\circ} \text { Foro Ciudadano Diálogo por la } \\
\text { democratización de los medios }\end{array}$ & $\begin{array}{l}16 \mathrm{de} \\
\text { noviembre }\end{array}$ \\
\hline XI Asamblea Nacional: \#YoSoy132 Xalapa & $\begin{array}{l}17 \text { de } \\
\text { noviembre }\end{array}$ \\
\hline 2ª Emisión de Radio \#YoSoy132Media & $\begin{array}{l}19 \text { de } \\
\text { noviembre }\end{array}$ \\
\hline $\begin{array}{l}\text { 1er Foro Ciudadano \#YoSoy132, } \\
\text { Diálogo por una agenda común para la } \\
\text { democratización de losmedios }\end{array}$ & $\begin{array}{l}22 \mathrm{de} \\
\text { noviembre }\end{array}$ \\
\hline $\begin{array}{l}6^{\text {a }} \text { Asamblea metropolitana \#YoSoy132 } \\
\text { (Metro Allende) }\end{array}$ & $\begin{array}{l}26 \mathrm{de} \\
\text { noviembre }\end{array}$ \\
\hline $\begin{array}{l}\text { Comunicado de Artistas Aliados para la } \\
\text { Manifestación del } 1^{\circ} \text { de diciembre }\end{array}$ & $\begin{array}{l}26 \text { de } \\
\text { noviembre }\end{array}$ \\
\hline $\begin{array}{l}\text { \#YoSoy132lnternacional emite consejos } \\
\text { para manifestaciones pacíficas del } 1^{\circ} \mathrm{de} \\
\text { diciembre }\end{array}$ & $\begin{array}{l}26 \text { de } \\
\text { noviembre }\end{array}$ \\
\hline Convoca \#YoSoy132 a ocupar San Lázaro & $\begin{array}{l}27 \text { de } \\
\text { noviembre }\end{array}$ \\
\hline $\begin{array}{l}\text { Convocatoria para Activistas para recabar } \\
\text { los hechos del } 1^{\circ} \text { de diciembre }\end{array}$ & $\begin{array}{l}1^{\circ} \text { de } \\
\text { diciembre }\end{array}$ \\
\hline $\begin{array}{l}\text { Comunicado de la Comisión de la } \\
\text { comunicación y prensa }\end{array}$ & 1 'de diciembre \\
\hline $\begin{array}{l}\text { Lista de detenidos \#YoSoy132 y su } \\
\text { ubicación }\end{array}$ & 2 de diciembre \\
\hline $\begin{array}{l}\text { Posicionamiento político de Acampada } \\
\text { Revolución } 132 \text { y convocatoria a Marcha }\end{array}$ & 2 de diciembre \\
\hline Marcha por los detenidos & 3 de diciembre \\
\hline $\begin{array}{l}\text { Asamblea Nacional \#YoSoy132 } \\
\text { Extraordinaria }\end{array}$ & 7 de diciembre \\
\hline $\begin{array}{l}\text { Salen libres bajo fianza los } 14 \text { presos del } \\
\text { \#YoSoy132 }\end{array}$ & $\begin{array}{l}28 \text { de } \\
\text { diciembre }\end{array}$ \\
\hline
\end{tabular}

Fuente: Modificado de Sierra (2014).

El definitiva, el momento histórico-político que transitó el \#YoSoy132 hace que se dinamicen sectores, como las instituciones públicas, las universidades, las organizaciones políticas, los gremios, los grupos minoritarios, entre otros, lo cual es una pauta necesaria para que se constituya el \#YoSoy132 como un movimiento "estudiantil, plural, propositivo", pero que debido a su insipiencia y promiscuidad no pudo pasar la barrera coyuntural, sino que se atascó en los repertorios, las denuncias y las demandas, mas no en una posición crítica de la realidad latinoamericana que no legitimara los poderes transnacionales y las políticas internacionales, lo cual se puede ver en el momento electoral y político frente a la elección de Enrique Peña Nieto.

Al mismo tiempo, se observa un movimiento con falta de experiencia y retroalimentación crítica para la circunstancias del momento, por ello, el \#YoSoy132 se fue dispersando y, en algunos momentos, su posible "identidad" en medio de la acción y la organización solo se percibió como un movimiento más; sin transcendencia 
y transformaciones sociales congruentes y verídicas para la ciudadanía mexicana.

A su vez, el \#YoSoy132 pasó a ser catalogado como un movimiento "frágil" para su momento histórico, y en efecto lo resultó, puesto que su base social se fue disgregando, ya que la focalización de los objetivos fu cada vez más débil, los cuales fueron aspectos que contrarrestaron las acciones, los repertorios y la legitimidad del movimiento tanto en su interior como en su exterior, lo cual deja en entredicho si se podría categorizar y definir como un fenómeno social, que se adscribe a los movimientos sociales latinoamericanos.

En últimas, el lenguaje y los significantes del movimiento responden a una tendencia eurocéntrica, puesto que en medio de sus peticiones buscaron legitimidad por organismos internacionales, lo cual es una contradicción, ya que los organismos internacionales están confabulados con las élites, los grupos burgueses y todos los sectores imperialistas que promulgan un discurso basado en la democratización de la "democracia mexicana”.

\section{CONCLUSIONES Y DISCUSIÓN}

Una de las características que constituyeron los aciertos y desaciertos del \#YoSoy132 resultó ser la falta de planificación frente a elementos, como la organización social, la base social, la legitimidad, los recursos, las oportunidades políticas, los momentos estructurales-coyunturales, pero, sobre todo, la incapacidad por generar posibles alternativas frente a la fuerte demanda proveniente de la ciudadanía.

Otro aspecto se encuentra en la identidad del \# YoSoy132, puesto que se aprecia una serie de espolones que tienen que ver con su programa de lucha y cómo en el interior del movimiento ese conjunto de comportamientos, nociones, emociones, se fueron entrelazando, tejiendo así un constructo socioafectivo en torno a los principios de base y a la simulación de organización del movimiento. A su vez, el conjunto de nociones que facilitaron la acción comunicativa dentro del movimiento y por fuera de él, como es el caso de propuestas como la democratización de los medios.
Lo anterior muestra que la identidad no tiene que ver con estados subjetivos o sentimientos colectivos o de pertenencia, se trata más bien de una propiedad del sistema en su conjunto, por lo que no está encarnada ni incorporada en partes proporcionales en cada uno de sus integrantes. Como producto de la diferencia sistema-entorno, la identidad supone, además, un constante vaivén entre auto- y heterorreferencia (Estrada, 2014).

Dichos procesos son constituyentes de los esquemas semánticos de causalidad y, por supuesto, del lenguaje de emociones, sensaciones y espontaneidad que configuran las razones y la base de organización del movimiento \# YoSoy132; por ello, las denotaciones de algunos políticos en contra de los alumnos de la Universidad Iberoamericana al llamarlos "porros".

Asimismo, encontramos que en su etapa de emergencia el \#YoSoy132 presenció un momento exploratorio del contagio que se puede observar en las circunstancias sociopolíticas, en las que emerge el movimiento en el momento en que el candidato presidencial Enrique Peña Nieto arremete contra ellos vulnerando su intimidad y estigmatizándolos como simpatizantes del partido contrario, o al denominarlos "porros". Igualmente, otro episodio donde el contagio se hace evidente resulta ser en el momento en el que se explora el comportamiento colectivo y se genera una simpatía y un virus por continuar con las manifestaciones y protestas en contra de la coyuntura político-electoral del momento (Capera, 2015).

En otro sentido, se aprecia la fuerte contienda entre demandas, acciones, denuncias y repertorios que son intrínsecos del movimiento, los cuales configuran su organización y base social "frágil". Las formas como se constituye el pronunciamiento (discurso) hacen que el contenido de los comunicados del \#YoSoy132 suene en algunos momentos "ingenuo", puesto que sus reclamos, quejas y exclamaciones (políticas) responden a las lógicas de la globalización, los procesos mercantilistas y las reformas del sistema neoliberal en América Latina, es decir, son contradicciones entre los discursos y las prácticas del movimiento estudiantil.

Igualmente la búsqueda de la "democratización”, que es un discurso liberal-burgués que re-produce las lógicas de una modernidad desbocada, líquida y en crisis, dado que se convierte en una apuesta proveniente de latitudes
| Características constituyentes de los aciertos y desaciertos frente a la conformación del movimiento estudiantil \#YoSoy132

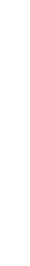


José Javier

Capera

Figueroa l

Sergio Alfonso

Huertas

Hernández I

Felipe Gabino

Macedo I

Macedo

En conclusión, una de las fallas estructurales del \#YoSoy132 como movimiento al tener una identidad estudiantil resultó ser la imposibilidad de canalizar los objetivos, las demandas y la organización, para así sobrellevar los escenarios de acciones conflictivas y saber focalizar el repertorio de acción colectiva, así como no sincronizar los aspectos donde el poder y la fuerza estaban en juego; para el caso de las oportunidades políticas el ser un agente movilizador de recursos, el cual nunca pudo definir, limitar y organizar plenamente sus objetivos, por ello, el movimiento desde su interior hasta su exterior evidenció crisis tanto en su forma de "representación" con la sociedad hasta en su ethos como "movimiento estudiantil", lo cual deja en entredicho sus dinámicas y acciones en búsqueda de las transformaciones sociales que tanto necesita la subsumida crisis de la realidad mexicana.

\section{REFERENCIAS BIBLIOGRÁFICAS}

1. Alberoni, F. (1984). Movimiento e institución. Madrid: Editora Nacional.

2. Aranda, J. (2000). El movimiento estudiantil y la teoría de los movimientos sociales. Convergencia, $21,225-250$.

3. Araya, D. (2012). Governance and Subpolitics in the Critical Political Theory of Boaventura de Sousa Santos. Perspectivas Rurales, 73-86.

4. Escobar, A. (1998). Cultures of Politics/Politics of Cultures: Re-visioning Latin American Social Movements. Boulder: WestviewPress.

Panorama I pp. 86-1021 Volumen 9 । Número 17 | Julio-diciembre I 2015 । Modernización reflexivapolitica, tradición y estética
7. Beck, U. (2001). La invención de lo político. México: Fondo de Cultura Económica.

8. Beck, U., Lash, S. y Giddens, A. (1997).

5. Bauman, Z. (2014). Jerusalem Versus Athens Revisited. En Ulrich Beck (pp. 71-75). Springer International Publishing.

6. Beck, U. (1998). La sociedad del riesgo: hacia una nueva modernidad. Madrid: Paidós Ibérica. en el orden social moderno. Madrid: Alianza.
9. Fals Borda, O. (1992). Social Movements and Political Power in Latin America. En S. Álvarez $\mathrm{y}$ A. Escobar, The making of social movements in Latin America. Identity, strategy, and democracy (pp.303-316). Oxford: Westview Press.

10. Beck, U. (1998). La sociedad del riesgo: hacia una nueva modernidad. Madrid: Paidós Ibérica.

11. Bourdieu, P. (2011). A miséria do mundo. Brasil: Vozes.

12. Bourdieu, P. (2013). La nobleza de estado. México: Siglo XXI.

13. Bourdieu, P., Wacquant, L. J. y Farage, S. (1994). Rethinking the State: Genesis and Structure of the Bureaucratic Field. Sociological Theory, 12, $1-1$.

14. Candón-Mena, J. (2013). Movimientos por la democratización de la comunicación: los casos del 15M y \#YoSoy132. Razón y Palabra, 82, 36-21.

15. Castells, M. (2004). La era de la información: economía, sociedad y cultura (vol. 3). Madrid: Siglo XXI.

16. Castells, M. (2011). The Power of Identity: The Information Age: Economy, Society, and Culture (vol. 2). Londres: John Wiley \& Sons.

17. De Sousa Santos, B. (2001). Los nuevos movimientos sociales. Osal, 5, 177-188.

18. Easton, D. (2006). Esquema para el análisis politico. Buenos Aires: Amorrortu.

19. Escobar, A. (1992). The Making of Social Movements in Latin America: Identity, Strategy, and Democracy. Boulder: Westview Press.

20. Estrada, M. (1995). Participación politica y actores colectivos. México: Universidad Iberoamericana/ Plaza y Valdés.

21. Estrada, M. (2014). Sistema de protesta: política, medios y el \#YoSoy132. Sociológica (México), 29(82), 83-123.

22. Giddens, A. (2013). The Third Way: The Renewal of Social Democracy. Londres: Wiley \& Sons.

23. Habermas, J. (1985). The Tasks of a Critical Theory of Society. En H. Jürgen, The Theory of Communicative Action (vol. 2, pp. 374-403). Boston: Beacon Press.

24. Harto de Vera, F. (2006). Ciencia politica y teoría política contemporáneas: una relación problemática. Madrid: Trota. 
25. Huertas, S. y Capera, J. (2015). ¿Cuáles son las concepciones teóricas y conceptuales que se logran identificar en la categoría de movilización social con respecto a los orígenes del movimiento indígena Manuel Quintín Lame? En II Congreso Nacional de Sociología: "La participación politica indigena: elementos para su análisis a partir de la teoria de la acción colectiva (pp.1-15). México: Universidad Autónoma del Estado de México.

26. Íñiguez, L. (2003). Movimientos sociales, conflicto, acción colectiva y cambio social. Barcelona: EDIOUC.

27. Jácome, A. (2010). Los movimientos sociales. En D. Soliz, Los movimientos sociales y el sujeto histórico (pp. 7-129). Quito: Flacso/ Secretaría de Pueblos, Movimientos Sociales y Participación Ciudadana.

28. Javaloy, F., Carballeira, A.y Espelt, E. (2001). Comportamiento colectivo y movimientos sociales: un enfoque psicosocial. Madrid: Pearson Educación.

29.

30. Laclau, E. \& Mouffe, C. (2004). Hegemonía y estrategia socialista: hacia una radi- calización de la democracia. Buenos Aires: Fondo de Cultura Económica de Argentina.

31. Lechner, N. (1981). Acerca del ordenamiento de la vida social por medio del Estado. Revista Mexicana de Sociología, 43(3), 1079-1102.

32. Luhmann, N. (1991). Sistemas sociales. México: Alianza.

33. Luhmann, N. (1998). Sistemas sociales: lineamientos para una teoría general (vol. 15). Madrid: Anthropos.

34. McAdam, D., McCarthy, J. D., \& Zald, M. N. (1996). Comparative perspectives on social movements: Political opportunities, mobilizing structures, and cultural framings. Cambridge University Press.

35. Marsh, D. y Stoker, G. (1997). Teoría y métodos de la ciencia politica. Madrid: Alianza.

36. Marsiske, R. (1999). Movimientos estudiantiles en la historia de América Latina. México: Plaza y Valdés.

37. Marti i Puig, S. (2010). Movimientos sociales. Recuperado de http://campus.usal.es/ dpublico/ areacp/materiales/Losmovimientossociales.pdf

38. Marwell, G., Oliver, P. E., \& Prahl, R. (1988). Social networks and collective action: A theory of the critical mass. III. American Journal of Sociology, 502-534.
39. Melucci, A. (1984). The New Social Movements: A Theoretical Approach. Social Science Information, 19(2), 199-226.

40. Melucci, A. (1985). The Symbolic Challenge of Contemporary Movements. Social Movements, 52(4), 789-816.

41. Melucci, A. (2012). Acción colectiva, vida cotidiana y democracia. México: COLMEX.

42. Mouffe, C. (2013). Agonistics: Thinking the World Politically. Londres y Nueva York: Verso Books.

43. Molina Orjuela, D. E. y Caicedo Córdoba, S. A. (2012). Movimientos sociales: visiones de alternatividad política desde Sur y Centro América: casos Bolivia, Ecuador, Brasil y México. Ars Boni et Aequi, 8(2), 211-250.

44. Orjuela, D. E. M., \& Córdoba, S. A. C. (2012). Movimientos sociales: visiones de alternatividad política desde Sur y Centro América: Casos: Bolivia, Ecuador, Brasil y México. Ars Boni et Aequi, 8(2), 211-250.

45. Parsons, T. (1999). El sistema social. Madrid: Alianza.

46. Pérez Ledesma, Manuel (1994). Cuando lleguen los días de la cólera. (Movimientos sociales, teoría e historia)., Zona Abierta, (69), 51-120.

47. Pont Vidal, J. (1998). La investigación de los movimientos sociales desde la sociología y la ciencia política: una propuesta de aproximación teórica. Papers: Revista de Sociología, 56, 257-272.

48. Prélot, M. (2002). La ciencia política. Buenos Aires: Eudeba.

49. Puig, S. (2010). Los movimientos sociales en un mundo globalizado: ¿alguna novedad? América Latina Hoy, 36, 79-100.

50. Rodríguez-Cabello, E. (1999). La construcción de los movimientos sociales. Madrid: Alianza.

51. Román Marugán, P. (2002). El descubrimiento de la sociedad y su politización: el nacimiento de los movimientos sociales. En J. Ferri Durá y P. Román Marugán (coords.), Los movimientos sociales: conciencia y acción de una sociedad politizada (pp. 9-22). Madrid: Consejo de la Juventud de España.

I Panorama

I pp. 86-102

52. Saavedra, M. (2012). Protesta social: tres estudios sobre movimientos sociales en clave de la teoría de los sistemas sociales de Niklas Luhmann. México: El Colegio de México AC.

\section{Características constituyentes de los aciertos y desaciertos frente a la} conformación del movimiento estudiantil \#YoSoy132 
53. Sierra, F. (2014). El movimiento estudiantil \#YoSoy132 (Tesis de maestría, Universidad Iberoamericana, México).

José Javier

Capera

Figueroa |

Sergio Alfonso

Huertas

Hernández I

Felipe Gabino

Macedo I

54. Imig, D., \& Tarrow, S. (1997). From strike to Eurostrike: The Europeanization of social movements and the development of a Euro-Polity., Working papar 97-10, Weatherhead Center for International Affairs, Hardvard University.

55. Tilly, C. (1998). Conflicto político y cambio social. In Los movimientos sociales: transformaciones politicas y cambio cultural (pp. 25-42). Madrid: Trotta.

56. Tarrow, S. (2010). The Strategy of Paired Comparison: Toward a Theory of Practice. Comparative Political Studies, 43(2), 230-259.

57. Tarrow, S. (2012). Strangers at the Gates: Movements and States in Contentious Politics. Londres: Cambridge University Press. 